Article

\title{
Are People Ready to Entrust Their Safety to an Autonomous Ambulance as an Alternative and More Sustainable Transportation Mode?
}

\author{
Azamat Zarkeshev *(D) and Csaba Csiszár ${ }^{\mathbb{D}}$ \\ Department of Transport Technology and Economics (KUKG) Budapest, Faculty of Transportation Engineering \\ and Vehicle Engineering (KJK), Budapest University of Technology and Economics (BME), Stoczek u. 2, \\ H-1111 Budapest, Hungary; csiszar.csaba@mail.bme.hu \\ * Correspondence: zarkeshev.azamat@mail.bme.hu
}

Received: 16 September 2019; Accepted: 7 October 2019; Published: 11 October 2019

check for updates

\begin{abstract}
Progress in advanced vehicular technologies and computer science leads to driverless vehicles becoming a reality. The standard ambulances might be replaced by driverless ambulances operated by an autopilot that provides passengers with a secure regime. Therefore, the study's aim was to collate two different countries regarding the consumers' preparedness to travel on such autonomous ambulances. To obtain a more demonstrative result, a questionnaire survey was conducted in two countries (Hungary and Kazakhstan). It also gathered 'affect' measures in order to figure out if 'affect' served as a medium between the ambulance mode and readiness to ride, and to understand whether emotions play any role during the decision making. The necessary data were collected through the so-called Autonomous Ambulance Acceptance Questionnaire. After conducting 't-Test', 'ANOVA', and Mediation analysis, the findings have been discussed. The results help to realize the necessity of developing educational guides to prepare potential patients for Autonomous Vehicles technology.
\end{abstract}

Keywords: readiness to ride; driverless ambulance; 'affect'; Autonomous Ambulance Acceptance Questionnaire; sustainable transportation mode

\section{Introduction}

The ambulance service plays an important role in healthcare worldwide. There are often no opportunities to respond to all incidents because of lack of equipment and staff at some ambulance stations [1]. However, transportation is going through a significant transformation due to rapid developments of info-communication technology and computer science [2-4]. As a result, autonomous driving technology has emerged. This technology has good potential for improvements in many different areas and particularly in healthcare. An Autonomous Vehicle (AV), which is also known as self-driving or driverless vehicle, is a car able to perceive the surroundings and drive without human intervention [5,6]. Whereas AVs are already present on the world's roads, some authorities are looking for the possibility of self-driving ambulance implementation [7]. For instance, South Central Ambulance Service (SCAS) took part in a UK trial of connected and autonomous vehicle (CAV) technology in Milton Keynes [8]. The purpose of the project was to test some of the latest technologies like automated driving, self-parking, and two connected car safety features. The first feature, which is an Emergency Vehicle Warning (EVW) system, alerts drivers about an ambulance approaching and also shows the direction it is coming from. It helps drivers to avoid panic and plan their movement in advance before they can see or hear an ambulance coming. The second feature is an Electronic Emergency Brake Light (EBBL) that warns if another connected car in front is sharply braking. It 
gives drivers a chance to avoid a possible collision. Such trials lead to the implication that in the future, traditional ambulances might be replaced by autonomous ones with the same amount of staff onboard. It causes more efficient medical care due to allowing both employees to work as a team on a patient when normally one of them would have to drive [9]. Working in a team may bring better results than individuals working alone [10]. Driverless ambulances may also decrease the risks related to drivers' imperfectness. Traffic accidents involving ambulances happen often [11] and ambulance service providers have a greater risk of fatal injury than some other professions because the most common fatal injuries occur in motor vehicle collisions [12]. Nowadays, the faults of drivers are the main cause of vehicle accidents. Due to the advent of AV technology, transportation has an opportunity to become more sustainable and secure [13].

There is an important question, despite the mentioned advantages-is a stricken individual ready to travel in an autonomous ambulance car? The reluctance of people to travel on AVs may become a serious obstacle to implement this technology in the ambulance service. Moreover, through understanding reasons of individual's readiness or reluctance to ride autonomous ambulance, it is possible to create educational guides for potential consumers before the autonomous driving technology becomes determinant. Thus, the research aim was to reveal the consumers' readiness to accept self-driving ambulances. To achieve more demonstrative results the studies were conducted in two different countries (Hungary and Kazakhstan). Another purpose was to define whether 'affect' acts as mediator between the traditional ambulance mode and autopilot mode. The so-called Autonomous Ambulance Acceptance Questionnaire (AAAQ) has been designed and applied for this purpose.

The remaining sections of the paper contain the following information: Section 2 provides a literature review about the related works; Section 3 describes the methodology of the research; data analysis, results, discussion are represented in Section 4; Section 5 provides the limitations to the current study; and the conclusion and future research directions are provided in Section 6.

\section{Related Work}

Automation in different areas of humans' life is a consequence of technological advancement. The human labor is replaced with automated equipment that performs different tasks [14]. However, in some situations, people feel anxiety about it. It is mentioned in several previous investigations that the level of automation trustworthiness influences the frequency of its introduction. [15-19]. Trust in terms of the psychological aspect means that the human or object acts as it was assumed [20-22]. This concept is also applicable to humans' trust in automation [23]. The relationship between trust and automation is defined [24] as transferring responsibility for the situation to another person or object, and the person transferring this responsibility expects that the one to whom it was transferred will meet their expectations. A previous research [25], in which five thousand people around the world were interviewed about the AV technology, showed that participants were worried about software hacking, safety, and legal issues. Respondents from countries with more a developed economy and advanced tech infrastructure were more anxious about the AVs' data transferring. Another research [26] explored the effect of information (negative and positive) on passengers' readiness to ride in self-driving cars. The outputs showed that positive information enhanced the desire to try AV while negative information decreased it. There is a hypothesis that users' feelings and their distrust of automation influence on this decrease in readiness to ride. The emergence of autonomous ambulances may cause the same reaction of reluctance to ride them because of emotional reasons, despite the obvious benefits without a decrease in safety. The purpose of this research is to examine people's readiness to use the driverless ambulance vehicle in contrast with a conventional one, and to compare and reveal correspondences.

There is a probability of gender difference in risk perception. Previous studies showed that sometimes males and females perceive things differently [27]. Some studies [28] demonstrated that males were greater risk takers than females, while others [29] clarified that females were fewer risk takers in almost $88 \%$ of the tasks. Some studies revealed that when an individual makes a decision, 'affect' has a significant role. [30,31]. In situations when fast issue resolution is required, people may 
rely on emotions because time is too limited to gather additional facts. Nevertheless, some researchers assume that humans make a forceful effort to get free of emotion when making a decision [32].

The researchers in 1971 investigated whether universal emotions exist, which could be accepted by humans regardless of their cultural differences [33]. The chosen emotions were as follows: angry, disgusted, scared, happy, sad, and surprised. Facial expression pictures were provided to various groups of people. Some of them were English speakers while others were not. Despite cultural differences, the findings showed that both children and adults could distinguish the feelings illustrated on the pictures $[34,35]$. These six facial expressions have been used in previous research to determine which feelings act as an 'intermediary'. The consumers' readiness to fly in a commercial aircraft was investigated regarding different regimes of configurations [36]. Other researchers [37] used this method to reveal perceptions about unmanned aerial vehicles (UAV). The findings showed that people were less worried about privacy when aerial vehicles were used for a concrete task as opposed to unceasingly used. Analysis of respondents' answers confirmed that emotions had a substantial meaning in them. The research demonstrated that fear and disgust acted as mediators in the relationship between UAV utilization and confidentiality.

\section{Methodology}

We performed a paper-based questionnaire survey to reveal the consumers' readiness to use an automated ambulance car in Hungary. At the same time, the online version of this questionnaire has been spread among the Kazakhstan citizens. The research questions were as follows: 1 . Are people ready to ride on an autonomous ambulance? 2. Does 'affect' serve as 'intermediary' between the ambulance mode and readiness to ride? 3. Which exact emotions among the six universal facial expressions act as mediums? The structure of the questionnaire is presented in Figure 1. Each section of the questionnaire is indicated by a box and includes a particular type of information (e.g., general information, multiple questions, etc.). These types are represented by different colors.

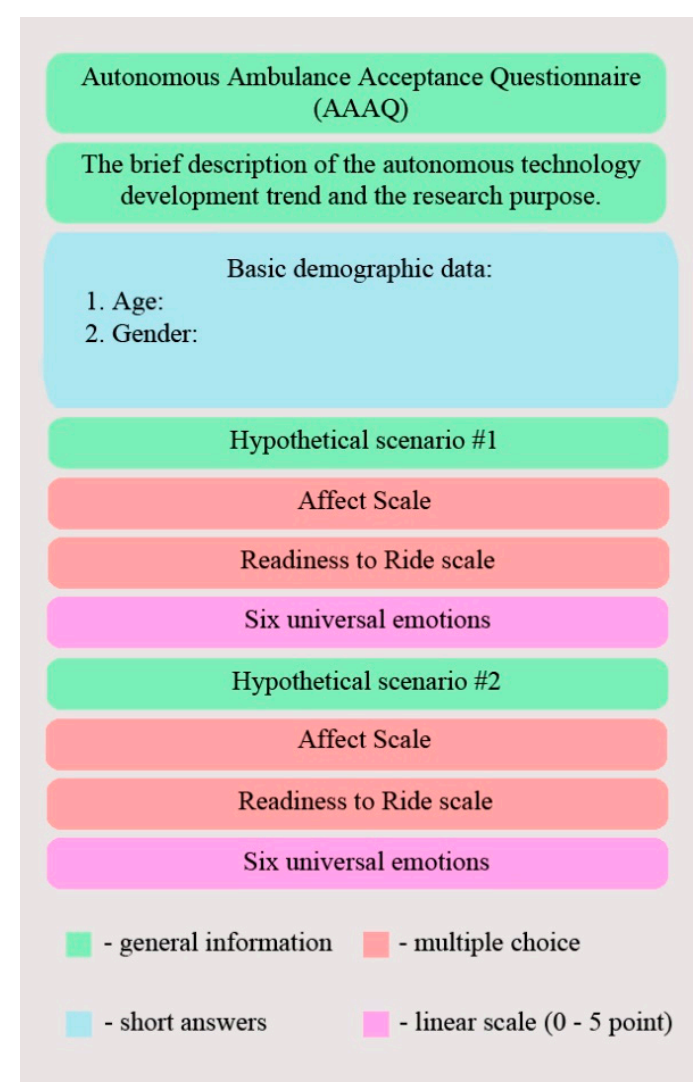

Figure 1. Structure of the questionnaire. 


\subsection{Participants}

We asked seventy students from Budapest University of Technology and Economics (Hungary) to fill the paper-based worksheet. At the same time, seventy people of different occupations from different cities (Kazakhstan) filled in the online survey using the 'Google Forms' tool. The sample used for the Hungarian survey is composed of students which, in our opinion, had a technical mindset and were more familiar with modern technologies than ordinary people. The sample used in Kazakhstan has not been clearly specified in order to compare the obtained answers with the above-mentioned category of respondents. Despite the fact that surveyed people were from different backgrounds, all of the participants were potential patients who hypothetically may be faced with a choice of ambulance mode. Nevertheless, the limitations of the study are described in the relevant section further. The demographic characteristics of respondents related to age are tabulated in Table 1. Standard Deviation (SD) and Mean values (M) were calculated for it. Results showed that in both countries, all the respondents are young adults.

Table 1. Sample characteristics. Standard Deviation, SD; Mean, M.

\begin{tabular}{ccc}
\hline Variables & Hungary & Kazakhstan \\
\hline Number of respondents & 70 & 70 \\
Age & & \\
M & 22.54 & 28.20 \\
SD & 2.95 & 7.54 \\
\hline
\end{tabular}

\subsection{Materials and Procedure}

Firstly, participants read a brief description of the autonomous technology development trend and the purpose of the study. Then, they were asked to fill out short questions about basic demographic data (age, gender). After that, two hypothetical scenarios about traditional ambulance cars and autonomous ambulance vehicles were provided to respondents.

The first scenario included the following information: 'You have called phone number 104 (103) asking for help because of an emergency situation. An ambulance vehicle arrived at your location to transport you to the infirmary. Traditionally configured vehicle is used where the driver sits in the cabin and a first-aid man is available in the back of the vehicle'.

The second scenario included the following information: 'You have called phone number 104 (103) asking for help because of an emergency situation. An ambulance vehicle arrived at your location to transport you to the infirmary. The vehicle is configured as follows: the driverless ambulance is operated in autopilot mode which means that there is no driver in the cabin and 2 paramedics instead of 1 provide you treatment in the back of the vehicle'.

Firstly, participants were given an 'affect' scale, which included the task of indicating the level of agreement or disagreement with the next assertions: 1 . This scenario evokes a good feeling for me. 2. This scenario evokes a positive feeling for me. 3. This scenario evokes a favorable feeling for me. 4. This scenario evokes a cheerful feeling for me. 5. This scenario evokes a happy feeling for me. The answers were ranged from 'strongly disagree' to 'strongly agree' according to the five-point 'Likert' Scale.

Some of the previous researches [38-41] showed that an 'affect' influences people's decisions regarding usage of AV. The 'affect' scale was developed based on the multistage process [42], which included consumers participating and testing in 3 scenarios involving more than 260 people.

Secondly, respondents were provided the scale of 'readiness to ride', which included the task of specifying the extent of agreement or disagreement with the next assertions: 1 . I am ready to ride according to this scenario. 2. I am comfortable to ride according to this scenario. 3. There is no problem for me to ride according to this scenario. 4. I am happy to ride according to this scenario. 
5. I feel safe about this scenario. The same respond options based on the 'Likert' Scale were provided to the respondents.

At the end of the questionnaire, we used the six universal emotions. Figure 2 represents these six universal facial expressions. Our hypothesis was that 'affect' might be 'intermediary' between the vehicle's mode and readiness to ride. Therefore, the experiment's aim lay on the exact definition of the feelings which served as mediums. The following task was provided to the respondents: 'With accordance to the hypothetical situation described above, at what extent do you feel that shown facial expression matches your feeling right now? Please, write your mark under each facial expression (in a range from 0 to 5 points)'. A similar method has been used by previous researchers [43-45].

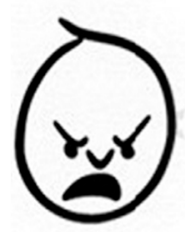

Anger

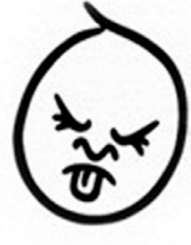

Disgust

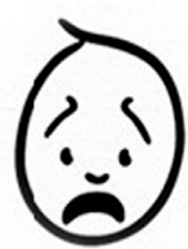

Fear

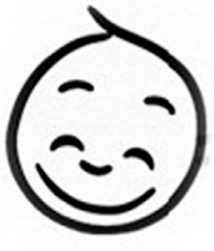

Happiness

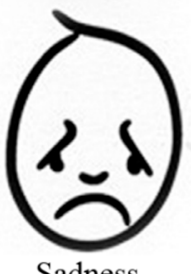

Sadness

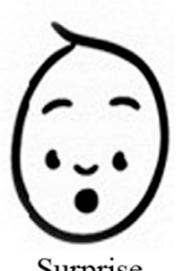

Surprise

Figure 2. Six universal facial expressions (source: [29]).

\section{Results and Discussion}

Before analyzing the data, the 'readiness to ride' (RTR) scale and 'affect' scales were processed by 'Cronbach's Alpha' tests to guarantee high data solidity. The results are represented in Table 2, which indicate high coherence in the data.

Table 2. 'Cronbach's Alpha' test outputs. Readiness to ride, RTR.

\begin{tabular}{ccccc}
\hline Mode & \multicolumn{2}{c}{ Hungary } & \multicolumn{2}{c}{ Kazakhstan } \\
\hline & RTR scale & 'Affect' scale & RTR scale & 'Affect' scale \\
\hline Traditional & 0.75 & 0.82 & 0.89 & 0.87 \\
\hline Autopilot & 0.84 & 0.80 & 0.94 & 0.94 \\
\hline
\end{tabular}

\section{1. 't-Test': Paired Two Samples for Mean Values (Hungary)}

A 'T-Test' was conducted in order to determine the divergence among the mean values for groups. The data obtained by the RTR scale were tested and the following results were obtained: $t(70)=2.88$ and $t_{c}$ (critical value $)=1.99$. As $t(70)>t_{c}$, this indicates considerable inequality between the two samples. $p=0.005$ is a value that defines whether results from the sample data occurred by chance. In this case $p<0.05(5 \%)$, which confirms that the data are valid and did not occur randomly. Cohen's $\mathrm{d}$ value has also been calculated to indicate the standardized difference between the two mean values. $\mathrm{d}=0.52$ represents a 'medium' effect size. In general, results showed that respondents were almost half as ready to travel in driverless mode $(\mathrm{M}=0.40, \mathrm{SD}=0.75)$ in contrast with a conventional ambulance $(\mathrm{M}=0.75, \mathrm{SD}=0.60)$. After that, the records acquired by using the 'affect' scale were processed via a ' $t$-Test' and the results were as follows: $t(70)=1.37, p=0.18$, and $d=0.20$. The outputs reflected that people experienced more negative feelings for $\mathrm{AVs}(\mathrm{M}=0.25, \mathrm{SD}=0.70)$ than for 'normal' ambulance vehicles $(M=0.39, S D=0.71)$. 


\section{2. 't-Test': Paired Two Samples for Mean Values (Kazakhstan)}

The results of the 't-Test' regarding RTR were as follows: $t(70)=2.76$ and $t_{c}=1.99$. $t(70)>t_{c}$, which shows a substantial distinction amongst the samples. $p=0.007$ and $p<0.05(5 \%)$, confirming that the data are valid and did not occur randomly. Cohen's $d=0.48$ represents a 'medium' effect size. In general, results clearly showed people's lesser readiness to ride in AVs $(\mathrm{M}=0.05, \mathrm{SD}=0.96)$ in contrast to conventional ambulances $(\mathrm{M}=0.45, \mathrm{SD}=0.68)$. Affect data results were as follows: $\mathrm{t}(70)=1.19, p=0.24$, and $\mathrm{d}=0.21$. This confirms that people had more negatory feelings towards the self-driving mode $(\mathrm{M}=0.13, \mathrm{SD}=0.89)$ as opposed to the 'standard' one $(\mathrm{M}=0.29, \mathrm{SD}=0.65)$. In Figure 3, the data of the mean values for groups are represented for both Hungary and Kazakhstan.

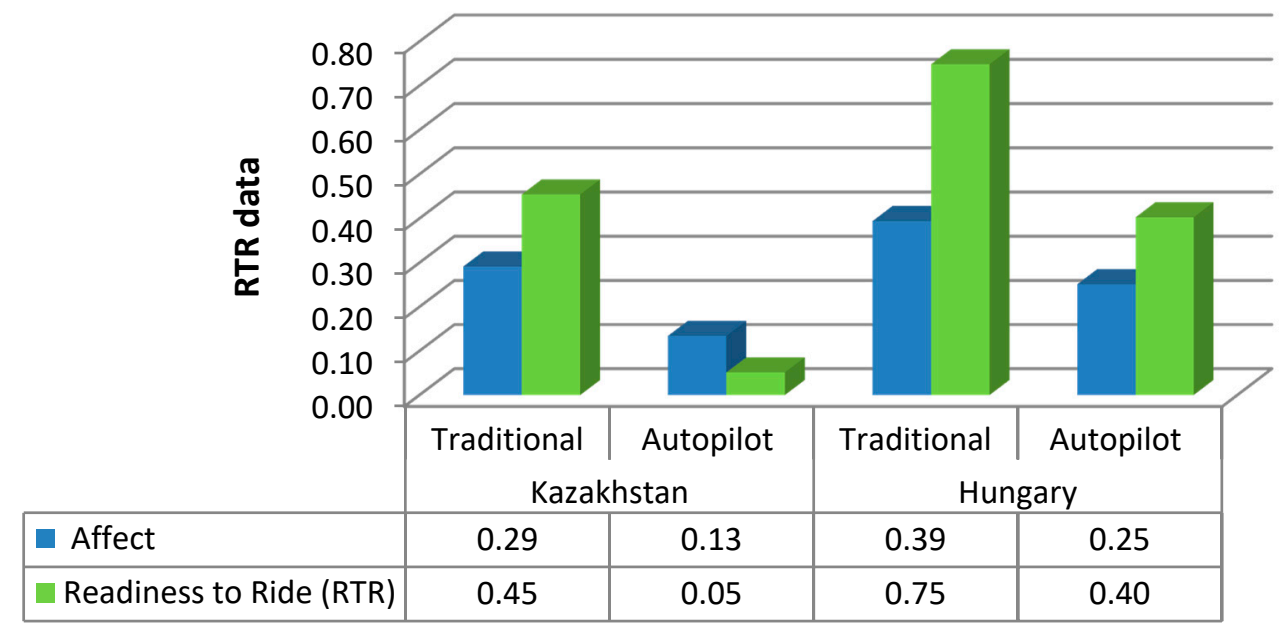

Figure 3. The data of the mean values for groups in Hungary and Kazakhstan.

\subsection{Two-Way 'ANOVA' Analysis (Hungary)}

A 2-way 'ANOVA' analysis was performed for RTR data where gender and ambulance mode were taken into account. The results showed a substantial main effect of the ambulance vehicle mode, $\mathrm{F}=6.03, p<0.05$, and partial eta ${ }^{2}=0.04$. No considerable effect was found for gender, $\mathrm{F}=0.97, p=0.32$, and partial eta ${ }^{2}=0.007$. Thus, we revealed a statistically substantial distinction in the readiness to ride by mode and a nonsignificant distinction in the readiness to ride by gender. The relationship between ambulance vehicle mode and gender is represented by a nonconsiderable main effect, $\mathrm{F}=0.00, p=0.99$, partial eta ${ }^{2}=0.00$, indicating that the variance of the dependent variable (RTR) cannot be attributed to the interaction between mode and gender. See Supplemental Materials.

\subsection{Two-Way 'ANOVA' Analysis (Kazakhstan)}

The results showed the substantial main effect of the ambulance car mode, $\mathrm{F}=6.91, p<0.05$, partial eta ${ }^{2}=0.048$. This means almost $5 \%$ of the variance in the dependent variable RTR can be attributed to ambulance mode. A nonconsiderable effect was detected for gender, $\mathrm{F}=0.72, p=0.39$, partial eta $^{2}=0.005$. Thus, we revealed a statistically substantial distinction in the readiness to ride by ambulance mode, but nonsignificant in the readiness to ride by gender. The relationship between ambulance vehicle mode and gender is represented by a nonconsiderable main effect, $\mathrm{F}=0.27$, $p=0.6$, partial eta ${ }^{2}=0.002$, indicating that the variance of the dependent variable (RTR) cannot be attributed to the interaction between mode and gender. Figure 4 illustrates the RTR results. See Supplemental Materials. 


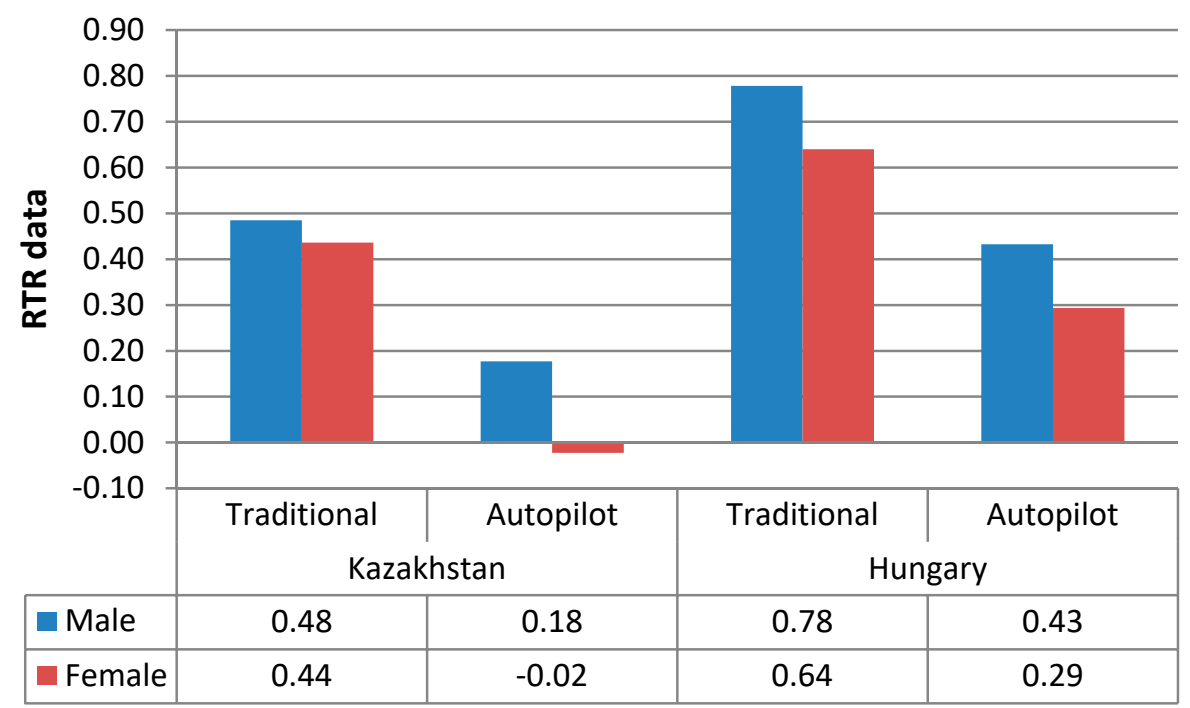

Figure 4. RTR data in accordance with ambulance mode and gender for both Hungary and Kazakhstan.

\subsection{Mediation Analysis (Hungary)}

Mediation analysis was conducted in order to identify whether 'affect' acts as an 'intermediary' between ambulance mode and readiness to ride [46]. For the analysis, 10,000 bootstraps were used. The mediation model that has been tested is represented in Figure 5.

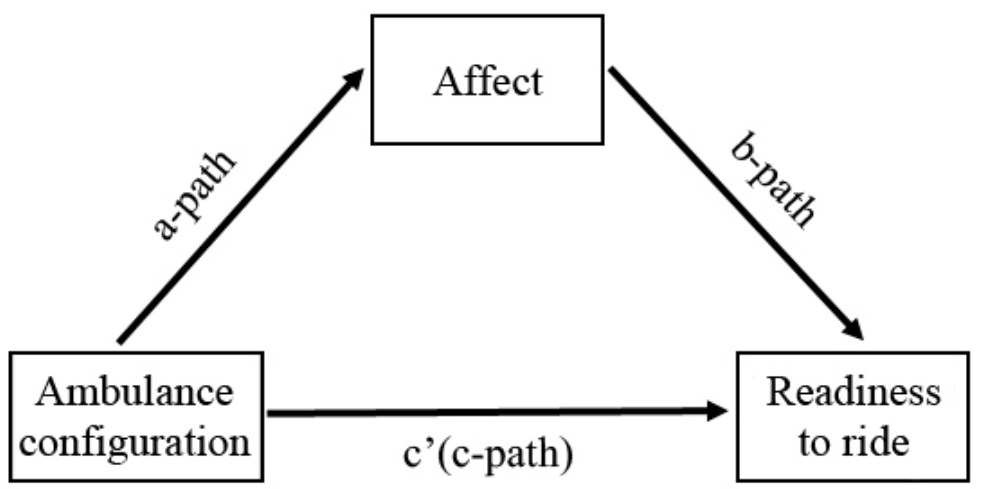

Figure 5. Indirect effect of 'ambulance mode' on 'readiness to ride' via 'affect'.

Results of the mediation analysis did not confirm the intermediary role of 'affect' between 'ambulance mode' and 'readiness to ride'. 'Indirect effect' was not found to be statistically substantial (beta $\mathrm{B}=-0.07$; confidence interval $\mathrm{CI}=-0.22$ to 0.04 ). As opposed to a conclusion drawn by [47], the findings suggest that consumers' emotions did not play a key role in their responses to their readiness to ride. To confirm this statement, mediation analysis for each facial expression for both males and females was performed. Figure 6 represents which exact emotions were prevalent among the respondents.

Despite the fact that 'fear' and 'surprise' were expressed at a significant level for both males and females towards the autopilot condition, none of the six universal emotions were found as a mediator during the mediation analysis neither for males nor females. The indirect effect after all 12 mediation analyses showed statistically insignificant values, and a confidence interval ranging from negative to positive values which included 0 . 


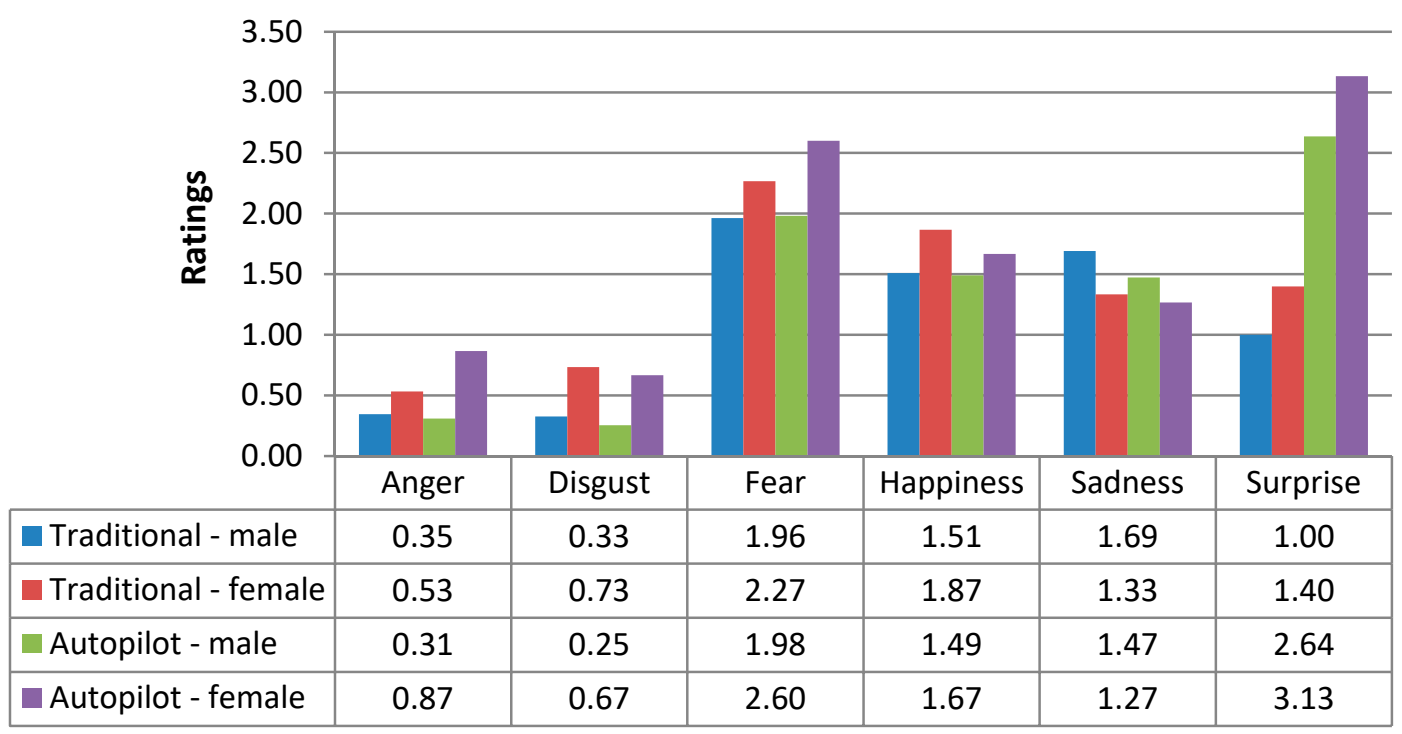

Figure 6. Affect data based on universal facial expressions according to mode and gender (Hungary).

\subsection{Mediation Analysis (Kazakhstan)}

Results of the mediation analysis did not confirm the intermediary role of 'affect' between 'ambulance mode' and 'readiness to ride'. 'Indirect effect' was not found to be statistically substantial (beta $\mathrm{B}=-0.14$; confidence interval $\mathrm{CI}=-0.38$ to 0.09 ). Thus, the findings suggest that consumers' emotions did not play a decisive role in their answers about their readiness to ride. To confirm this statement, mediation analysis for each facial expression for both males and females was performed. Figure 7 represents which exact emotions were prevalent among the respondents.

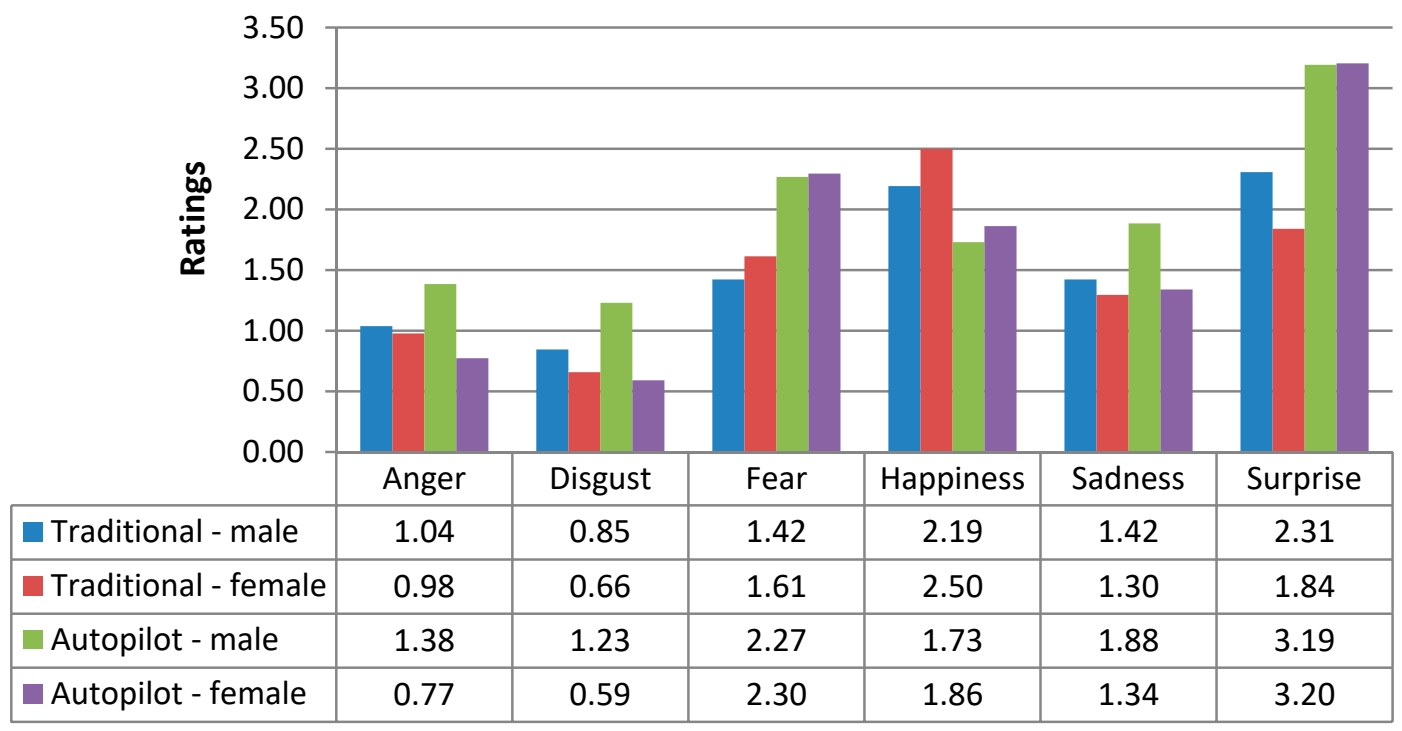

Figure 7. Affect data based on six universal emotions according to mode and gender (Kazakhstan).

Despite the fact, that 'fear' and 'surprise' were clearly prevalent compared to other emotions towards the autopilot condition, the mediation role was rejected for all six universal emotions for both males and females. The indirect effect after all 12 mediation analyses showed statistically insignificant values, and a confidence interval ranging from negative to positive value which included 0 . 


\subsection{General Discussion}

The findings showed that ambulance mode considerably influences the readiness to ride. In both countries, people unambiguously stated unreadiness to ride in autonomous ambulance and expressed mostly negatory feelings in relation with this mode. The results also demonstrated that respondents from Kazakhstan were less trusting to both traditional and autopilot ambulance modes than Hungarian consumers. However, consumers' emotions did not play a decisive role in their answers about their readiness to ride, because none of the six universal emotions were found as a mediator during the mediation analysis neither for males nor females. This conclusion is the same for both Hungary and Kazakhstan. The novelty of the AVs and thus the lack of trust and knowledge about them might be the main obstacle for perception of an automated ambulance mode. Education could increase awareness and trust of consumers. As mentioned in [47], the gradual introduction of autonomous ambulance technology through trial transportation of patients with noncritical injuries may enhance users' trust and lead to the spread of this technology. Despite the fact that driverless vehicle technology is becoming available, scientists and innovators have to take into account the readiness of its acceptance by travelers. We also found that readiness to ride is not influenced by gender and the variance in the dependent variable (RTR) cannot be attributed to the interaction between mode and gender.

\section{Release of Limitations, Outlook}

Several limitations have been introduced to this research. The hypothetical scenarios considerably influenced the answers of participants. The results might be distinguished from the real-life scenario. Additionally, in Hungary, data were collected only from young students at Budapest University of Technology and Economics and, in Kazakhstan, from young people with a different background and activity. That means the outputs should not be generalized beyond those types of participants that responded to our questionnaire. Also, wide demographic participation cannot be justified because only age and gender were collected as demographic data. The research proposed only one script describing an undefined emergency situation. Extra scenarios in which the participant is in another role than the patient (e.g., a medical service provider) could also be studied. Moreover, scenarios representing various levels of emergency severity could show users decision towards readiness to travel on autonomous ambulances and their behavior in conditions of limited time for making decisions. It could lead to an understanding of the veracity of participants' answers, or, in summary, that readiness to ride depends only on the severity of the emergency.

\section{Conclusions}

AV technology is getting more and more mature year by year. This may lead to the advent of driverless ambulances. However, the consumers' readiness to accept it must be taken into account before the introduction.

The main contributions of the paper are the following:

- A questionnaire survey to measure users' readiness to ride in self-driving ambulances.

- Analysis of the data received from respondents according to several aspects.

We found:

- People are obviously less ready to ride in, and have more negatory feelings toward an autonomous vehicle in contrast to a traditional one.

- Participants from Kazakhstan are less ready to travel in both traditional and driverless ambulance modes than Hungarian consumers.

- Participants from Kazakhstan demonstrated more negative emotions towards both conditions than Hungarian consumers.

- There is a statistically substantial distinction in readiness to ride according to mode and a nonsignificant one in readiness to ride according to gender. 
- The variance in the dependent variable (RTR) cannot be attributed to the interaction between mode and gender.

- Consumers' emotions did not play a key role in their responses regarding their readiness to ride.

- None of the six universal emotions were found as a mediator during the mediation analysis, neither for males nor females.

Our future research plans include:

- Extend and replicate the study involving participants with different ages and occupations to figure out whether results are the same or what the differences are.

- Study the Emergency Medical Service (EMS) providers applying the same approach.

- Proceed with the research by elaboration and investigation of more complex scenarios.

Supplementary Materials: The following are available online at http://www.mdpi.com/2071-1050/11/20/5595/s1, data sample for Kazakhstan, data sample for Hungary, source files of ANOVA, mediation analysis, and Cohen's d calculation.

Author Contributions: Conceptualization, A.Z. and C.C.; methodology, A.Z. and C.C.; validation, C.C.; data curation, A.Z.; writing —original draft preparation, A.Z. and C.C.; writing—review and editing, A.Z. and C.C.

Funding: This research received no external funding.

Acknowledgments: The research reported in this paper was supported by the Higher Education Excellence Program in the frame of Artificial Intelligence research area of Budapest University of Technology and Economics (BME FIKP-MI/FM).

Conflicts of Interest: The authors declare no conflict of interest.

\section{References}

1. Szél, D. Hungarian Ambulance Service Forces Drivers to Perform Nurse Duties. Daily News Hungary. 2018. Available online: https://dailynewshungary.com/hungarian-ambulance-service-forces-drivers-to-performnurse-duties/ (accessed on 7 September 2019).

2. Tettamanti, T.; Varga, I.; Szalay, Z. Impacts of Autonomous Cars from a Traffic Engineering Perspective. Period. Polytech. Transp. Eng. 2016, 44, 244-250. [CrossRef]

3. Szalay, Z.; Nyerges, Á.; Hamar, Z.; Hesz, M. Technical Specification Methodology for an Automotive Proving Ground Dedicated to Connected and Automated Vehicles. Period. Polytech. Transp. Eng. 2017, 45, 168-174. [CrossRef]

4. Szalay, Z.; Tettamanti, T.; Esztergár-Kiss, D.; Varga, I.; Bartolini, C. Development of a Test Track for Driverless Cars: Vehicle Design, Track Configuration, and Liability Considerations. Period. Polytech. Transp. Eng. 2018, 46, 29-35. [CrossRef]

5. Anderson, J.M.; Kalra, N.; Stanley, K.D.; Sorensen, P.; Samaras, C.; Oluwatola, O. Autonomous Vehicle Technology: A Guide for Policymakers; Rand Corporation: Santa Monica, CA, USA, 2016. [CrossRef]

6. Kuo, P.-H.; Krishnamurthy, A.; Malmborg, C.J. Design models for unit load storage and retrieval systems using autonomous vehicle technology and resource conserving storage and dwell point policies. Appl. Math. Model. 2007, 31, 2332-2346. [CrossRef]

7. Connected and Autonomous Vehicles: The Future? 2017. Available online: https://publications.parliament. uk/pa/ld201617/ldselect/ldsctech/115/11505.htm\#footnote-224 (accessed on 30 September 2019).

8. South Central Ambulance Service NHS Foundation Trust (SCAS). SCAS Joins UK's Largest Autonomous and Connected Vehicle Project. 2019. Available online: https://www.scas.nhs.uk/scas-joins-uks-largestautonomous-and-connected-vehicle-project/ (accessed on 30 September 2019).

9. Hughes, A.; Gregory, M.; Joseph, D.; Sonesh, S.C.; Marlow, S.L.; Lacerenza, C.; Benishek, L.E.; King, H.B.; Salas, E. Saving lives: A meta-analysis of team training in healthcare. J. Appl. Psychol. 2016, 101, 1-39. [CrossRef]

10. Marks, M.A.; Mathieu, J.E.; Zaccaro, S.J. A Temporally Based Framework and Taxonomy of Team Processes. Acad. Manag. Rev. 2001, 26, 356-376. [CrossRef]

11. Smith, N. A national perspective on ambulance crashes and safety. EMS World 2015, 44, 91-92. 
12. Jaynes, C. The price of safety: Comparing the return on investment in safe driving systems. JEMS J. Emerg. Med. Serv. 2016, 41, 44-48.

13. Jing, P.; Huang, H.; Ran, B.; Zhan, F.; Shi, Y. Exploring the Factors Affecting Mode Choice Intention of Autonomous Vehicle Based on an Extended Theory of Planned Behavior-A Case Study in China. Sustainability 2019, 11, 1155. [CrossRef]

14. Wickens, C.D.; Hollands, J.G.; Banbury, S.; Parasuraman, R. Engineering Psychology and Human Performance; Psychology Press: London, UK, 2015; p. 544, ISBN 1317351320, 9781317351320.

15. Geels-Blair, K.; Rice, S.; Schwark, J. Using system-wide trust theory to reveal the contagion effects of automation false alarms and misses on compliance and reliance in a simulated aviation task. Int. J. Aviat. Psychol. 2013, 23, 245-266. [CrossRef]

16. Parasuraman, R.; Riley, V. Humans and automation: Use, misuse, disuse, abuse. Hum. Factors J. Hum. Factors Ergon. Soc. 1997, 39, 230-253. [CrossRef]

17. Rice, S.; Geels, K. Using system-wide trust theory to make predictions about dependence on four diagnostic aids. J. Gen. Psychol. 2010, 137, 362-375. [CrossRef] [PubMed]

18. Rice, S. Examining- and multiple-process theories of trust in automation. J. Gen. Psychol. 2009, 136, $303-319$. [CrossRef] [PubMed]

19. Földes, D.; Csiszár, C.; Zarkeshev, A. User expectations towards mobility services based on autonomous vehicle. In Proceedings of the 8th International Scientific Conference CMDTUR, Žilina, Slovakia, 4-5 October 2018; pp. 7-15, ISBN 978-80-554-1485-0.

20. Deutsch, M. Trust and suspicion. J. Confl. Resolut. 1958, 2, 265-279. [CrossRef]

21. Eckel, C.C.; Wilson, R.K. Is trust a risky decision? J. Econ. Behav. Organ. 2004, 55, 447-465. [CrossRef]

22. Ergeneli, A.; Saglam, G.; Metin, S. Psychological empowerment and its relationship to trust in immediate managers. J. Bus. Res. 2007, 60, 41-49. [CrossRef]

23. Reeves, B.; Nass, C. The Media Equation: How People Treat Computers, Television, and New Media Like Real People and Places; Cambridge University Press: Cambridge, UK, 1996.

24. Mayer, R.C.; Davis, J.H.; Schoorman, F. An integrative model of organizational trust. Acad. Manag. Rev. 1995, 20, 709-734. [CrossRef]

25. Kyriakidis, M.; Happee, R.; Winter, J.C.F. Public opinion on automated driving: Results of an international questionnaire among 5000 respondents. Transp. Res. Part F Traffic Psychol. Behav. 2015, 32, 127-140. [CrossRef]

26. Anania, E.C.; Rice, S.; Walters, N.W.; Pierce, M.; Winter, S.R.; Milner, M.N. The effects of positive and negative information on consumers' willingness to ride in a driverless vehicle. Transp. Policy 2018, 72, 218-224. [CrossRef]

27. Schubert, R.; Brown, M.; Gysler, M.; Brachinger, H.W. Financial decision-making: Are women really more risk-averse? Am. Econ. Rev. 1999, 89, 381-385. [CrossRef]

28. Powell, M.; Ansic, D. Gender differences in risk behaviour in financial decision-making: An experimental analysis. J. Econ. Psychol. 1997, 18, 605-628. [CrossRef]

29. Byrnes, J.P.; Miller, D.C.; Schafer, W.D. Gender differences in risk taking: A meta-analysis. Psychol. Bull. 1999, 125, 367-383. [CrossRef]

30. Schwarz, N. Emotion, cognition, and decision making. Cogn. Emot. 2000, 14, 433-440. [CrossRef]

31. Bechara, A. The role of emotion in decision-making: Evidence from neurological patients with orbitofrontal damage. Brain Cogn. 2004, 55, 30-40. [CrossRef] [PubMed]

32. Sayegh, L.; Anthony, W.P.; Perrewe, P.L. Managerial decision-making under crisis: The role of emotion in an intuitive decision process. Hum. Resour. Manag. Rev. 2004, 14, 179-199. [CrossRef]

33. Ekman, P.; Friesen, W.V. Constants across cultures in the face and emotion. J. Personal. Soc. Psychol. 1971, 17, 124-129. [CrossRef] [PubMed]

34. Ekman, P.; Friesen, W.V.; Hagar, J.C. Facial Action Coding System Investigators Guide; Research Nexus: Salt Lake City, UT, USA, 2002.

35. Ekman, P.; Sorenson, E.R.; Friesen, W.V. Pan-cultural elements in facial displays of emotion. Science 1969, 164, 86-88. [CrossRef]

36. Rice, S.; Winter, S.R. Which emotions mediate the relationship between type of pilot configuration and willingness to fly? Aviat. Psychol. Appl. Hum. Factors 2015, 5, 83-92. [CrossRef]

37. Winter, S.R.; Rice, S.; Tamilselvan, G.; Tokarski, R. Mission-based citizen views on UAV usage and privacy: An affective perspective. J. Unmanned Veh. Syst. 2016, 4, 125-135. [CrossRef] 
38. Babin, B.J.; Attaway, J.S. Atmospheric affect as a tool for creating value and gaining share of customer. J. Bus. Res. 2000, 49, 91-99. [CrossRef]

39. Baker, J.; Cameron, M. The effects of the service environment on affect and consumer perception of waiting time: An integrative review and research propositions. J. Acad. Mark. Sci. 1996, 24, 338-349. [CrossRef]

40. Campbell, M.C. Says who? How the source of price information and affect influence perceived price (un) fairness. J. Mark. Res. 2007, 44, 261-271. [CrossRef]

41. Winter, S.R.; Rice, S.; Mehta, R. Aviation consumers' trust in pilots: A cognitive or emotional function. Int. J. Aviat. Aeronaut. Aerosp. 2014, 1, 2. [CrossRef]

42. Jian, J.; Bisantz, A.M.; Drury, C.G. Foundations for an empirically determined scale of trust in automated systems. Int. J. Cogn. Ergon. 2000, 4, 53-71. [CrossRef]

43. Cremer, I.; Rice, S. Which emotions mediate the relationship between type of water recycling projects and likelihood of using green airports. Int. J. Sustain. Aviat. 2015, 1, 299-313. [CrossRef]

44. Rice, S.; Winter, S. A quick affect scale: Providing evidence for validity and reliability. In Proceedings of the 10th International Conference on Interdisciplinary Social Sciences, Split, Croatia, 11-14 June 2015.

45. Rice, S.; Kraemer, K.; Mehta, R. Which emotion(s) mediate the relationship between mental illness and trust? Issues Soc. Sci. 2015, 3, 132. [CrossRef]

46. Hayes, A.F. Introduction to Mediation, Moderation, and Conditional Process Analysis, 2nd ed.; A Regression-Based Approach; Guilford Publications: New York, NY, USA, 2017; ISBN 9781462534654.

47. Winter, S.R.; Keebler, J.R.; Rice, S.; Mehta, R.; Baugh, B.S. Patient perceptions on the use of driverless ambulances: An affective perspective. Transp. Res. Part F Traffic Psychol. Behav. 2018, 58, 431-444. [CrossRef]

(C) 2019 by the authors. Licensee MDPI, Basel, Switzerland. This article is an open access article distributed under the terms and conditions of the Creative Commons Attribution (CC BY) license (http://creativecommons.org/licenses/by/4.0/). 